\title{
Clustering Menggunakan Metode K-Means Untuk Menentukan Prioritas Penerima Bantuan Bedah Rumah (Studi Kasus : Desa Ciomas Bogor)
}

\author{
Yahdi Kusnadi $^{1 *)}$, Mardiani Subagio Putri ${ }^{2)}$ \\ 1) Universitas Bina Sarana Informatika Jakarta \\ ${ }^{2)}$ STMIK Nusa Mandiri Jakarta \\ ${ }^{*}$ Correspondence Author: yahdi.ydk@ bsi.ac.id, Jakarta, Indonesia \\ DOI: https://doi.org/10.37012/jtik.v7i1.498
}

\begin{abstract}
Abstrak
Penduduk miskin di Indonesia selalu menjadi permasalahan. Setiap pimpinan daerah maupun pusat menjadikan penduduk miskin sebagai tujuan utama yang harus diselesaikan. Bantuan bedah rumah sangat dibutuhkan. Berdasarkan evaluasi pelaksanaaan program bantuan ini, masih terdapat penyaluran yang tidak tepat sasaran. Penelitian ini mencoba mengelompokkan (mengkluster) penduduk miskin yang menjadi prioritas utama untuk mendapatkan bantuan bedah rumah dengan menggunakan metode K-Means. Metoda ini terdiri dari 3 pertimbangan kriteria yaitu jenis atap, jenis dinding dan jenis lantai. Nilai dari setiap kriteria tersebut menjadi patokan untuk penyeleksian penduduk yang menjadi prioritas utama untuk mendapatkan bantuan bedah rumah. Pada penelitian ini penduduk yang berhak mendapatkan bantuan bedah rumah adalah penduduk yang mempunyai nilai cluster paling besar atau kondisi fisik rumah terburuk. Sistem penilaian prioritas penduduk miskin menggunakan data mining metode Clustering K-Means. Sistem ini dapat dipergunakan sebagai salah satu metode pengklasteran yang membantu keputusan dalam menentukan kelompok penduduk prioritas yang mendapatkan bedah rumah. Penelitian ini dapat menjadi acuan Kepala Desa agar penilaian prioritas penduduk penerima bantuan bedah rumah bisa lebih berkualitas dan efektif.
\end{abstract}

Kata Kunci: Data Mining, Clustering, K-Means, Bantuan Bedah Rumah

\begin{abstract}
The poor in Indonesia have always been a problem. Every regional and central leadership makes the poor as the main goal that must be resolved. Home renovation assistance is needed. Based on the evaluation of the implementation of this assistance program, there are still disbursements that are not on target. This study tries to group (cluster) the poor who are the top priority for housing assistance using the K-Means method. This method consists of 3 criteria considerations, namely the type of roof, the type of walls and the type of floor. The value of each of these criteria becomes the benchmark for selecting the population who is the top priority for housing assistance. In this study, residents who are entitled to house renovation assistance are those who have the greatest cluster value or the worst physical condition of the house. The priority assessment system for the poor uses the Clustering K-Means data mining method. This system can be used as a clustering method that assists decisions in determining priority population groups to receive house renovations. This research can be used as a reference for the Village Head so that the priority assessment of the population receiving house renovation assistance can be of higher quality and effectiveness
\end{abstract}

Keywords: Data Mining, Clustering, K-Means, Housing Assistance

\section{PENDAHULUAN}

Dengan kemajuan teknologi informasi dewasa ini, kebutuhan akan informasi yang akurat sangat dibutuhkan dalam kehidupan sehari-hari, sehingga informasi menjadi suatu elemen penting dalam perkembangan masyarakat saat ini dan waktu mendatang. 
Perumahan dan pemukiman merupakan salah satu kebutuhan dasar manusia dan faktor penting dalam peningkatan harkat dan martabat manusia Indonesia. Perlu adanya penciptaan kondisi yang dapat mendorong pembanguan perumahan untuk menjaga kelangsungan penyediaan perumahan dan pemukiman.

Jumlah rumah tak layak huni sekitar 2,51 juta unit dengan rincian 2,18 juta rawan layak huni dan 0,33 juta benar-benar tak layak huni. Menanggapi masalah tersebut, banyak bantuan renovasi rumah yang ditawarkan kepada masyarakat yang memang membutuhkan. Berdasarkan evaluasi pelaksanaan program bantuan stimulant perumahan swadaya, masih terdapat penyaluran bantuan yang tidak tepat sasaran.

Masalah pada penelitian ini adalah bagaimana mengelompokkan (mengklaster) penduduk miskin yang menjadi prioritas utama untuk mendapatkan bantuan bedah rumah. Masalah berikutnya adalah bagaimana mengolah data penduduk miskin yang ada dengan pertimbangan kriteria diantaranya Jenis Atap, Jenis Dinding, dan Jenis Lantai. Kemudian nilai dari setiap kriteria tersebut menjadi patokan untuk penyeleksian penduduk yang akan menjadi prioritas utama untuk mendapatkan bantuan bedah rumah.

Penelitian sebelumnya yang terkait dengan tema serupa adalah penelitian yang dilakukan oleh Sarjono, mahasiswa STIKOM Dinamika Bangsa, Jambi. Pada penelitian tersebut membahas tentang sistem penilaian prioritas penduduk yang tidak mampu, menggunakan metode Clustering K-Means sehingga dapat diketahui prioritas rumah yang layak menerima bantuan bedah rumah.

Penelitian berikutnya dengan judul "Clustering Menggunakan Metode K-Means Untuk Menentukan Status Gizi Balita (Studi kasus: Desa Karang Songo)” penelitian yang dilakukan oleh Windha Mega, mahasiswi STIKOM AMIKOM Yogyakarta membahas tentang pengelompokkan gizi balita, menggunakan metode Clustering K-Means sehingga dapat diketahui status gizi balita didaerah tersebut.

Penelitian yang terkait dengan tema serupa juga adalah penelitian yang dilakukan oleh Surmayanti dkk, mahasiswi Universitas Putra Indonesia, YPTK Padang. Pada penelitian tersebut membahas tentang penerapan analysis Clustering pada penjualan komputer dengan perancangan aplikasi data mining menggunakan algoritma K-Means (Studi kasus: Toko Tri Buana Komputer Kota Solok) sehingga dapat diketahui jenis barang yang mudah terjual.

Dari penelitian yang telah dilakukan sebelumnya dengan tema serupa dapat menjadi acuan dalam penelitian yang akan dilakukan penulis yaitu Clustering Menggunakan Metode KMeans Untuk Menentukan Prioritas Penerima Bantuan Bedah Rumah Di Desa Ciomas. 
Dengan penelitian ini diharapkan dapat membantu menyelesaikan permasalahan seleksi penerima bantuan bedah rumah di Desa Ciomas, Bogor.

\section{METODE}

Data mining adalah proses yang menggunakan teknik statistik, matematika, kecerdasan buatan dan machine learning untuk mengekstraksi dan mengidentifikasi informasi yang bermanfaat dan pengetahuan yang terakit dari berbagai database besar.

Data mining juga dapat diartikan sebagai pengekstrakan informasi baru yang diambil dari bongkahan data besar yang membantu dalam mengambil keputusan. Istilah data mining kadang disebut juga knowledge discovery.

K-Means menggunakan pendekatan partitional clustering. Tiap cluster dihubungkan dengan sebuah centroid (titik pusat). Tiap titik pusat ditempatkan ke dalam cluster dengan centroid terdekat. Jumlah cluster, K, harus ditentukan. Algoritma dasarnya sangat sederhana, yaitu :

1. Pilih K titik sebagai centroid awal

2. Ulangi

a. Bentuk K cluster dengan menempatkan semua titik yang terdekat.

b. Ulangi perhitungan centroid dari tiap cluster.

3. Sampai centroid tidak berubah.

\section{HASIL DAN PEMBAHASAN}

Data penduduk miskin yang akan digali berdasarkan kriteria Jenis Atap, Jenis Dinding dan Jenis Lantai dalam suatu keluarga dikelompokkan ke dalam beberapa cluster. Dalam penelitian ini diambil sample 22 data penduduk tidak mampu di Desa Ciomas dan membaginya ke dalam 3 cluster yang dibatasi oleh 3 centroid. 
Tabel 1. Data Penduduk Miskin Desa Ciomas

\begin{tabular}{|c|c|c|c|c|c|c|c|c|}
\hline \begin{tabular}{l|l} 
No & Nama Kepala Keluarga \\
\end{tabular} & Pekerjaan & Atap & Dinding & Lantai & Sumber Penerangan & Sumber Air & Tanggungan & Pengeluaran \\
\hline 1 Mad Enoh Sp & Pegawai Swasta & Asbes & Tembok & Papan & Listrik PLN & PDAM & 3 & 3050000 \\
\hline 2 Ny. Atih & Tidak Bekerja & Asbes & Tembok & Papan & Listrik PLN & PDAM & 3 & 560000 \\
\hline 3 Nur Asiah & Tidak Bekerja & Asbes & Tembok & Papan & Listrik PLN & PDAM & 1 & 2385000 \\
\hline 4 Badri Kurniawan & Pedagang & Asbes & Bambu & Semen & Listrik PLN & PDAM & 3 & 2530000 \\
\hline 5 Supardi & Buruh & Asbes & Tripleks & Semen & Listrik PLN Sambung (Bayar) & PDAM & 5 & 1900000 \\
\hline 6 | Inot & Tidak Bekerja & Asbes & Tripleks & Semen & Listrik PLN Sambung (Bayar) & PDAM & 4 & 1550000 \\
\hline 7 Nenih & Buruh & Asbes & Tripleks & Semen & Listrik PLN Sambung (Bayar) & Sumur Bor & 0 & 1075000 \\
\hline 8 Suharsi & Pedagang & Genteng & Tripleks & Papan & Listrik PLN & PDAM & 2 & 2800000 \\
\hline 9 Ahmad Halim & Pedagang & Genteng & Bambu & Semen & Listrik PLN & Sumur Bor & 2 & 1415000 \\
\hline 10|Manang & Pedagang & Genteng & Bambu & Semen & Listrik PLN & Sumur Bor & 3 & 1490000 \\
\hline 11 Anang & Buruh & Genteng & Tripleks & Semen & Listrik PLN Sambung (Bayar) & PDAM & 2 & 3000000 \\
\hline 12 Yahya & Tidak Bekerja & Genteng & Papan & Keramik & Listrik PLN & Sumur Bor & 6 & 565000 \\
\hline 13 Dona Nofriansyah & Pegawai Swasta & Genteng & Papan & Keramik & Listrik PLN & Sumur Bor & 1 & 5086000 \\
\hline 14 Abud Suhardiman & Pengemudi & Genteng & Papan & Keramik & Listrik PLN & PDAM & 2 & 5750000 \\
\hline 15 Undan Rusmana & Pegawai Swasta & Genteng & Papan & Keramik & Listrik PLN & Sumur Bor & 2 & 3150000 \\
\hline 16) Ellis Suharti & Tidak Bekerja & Genteng & Papan & Keramik & Listrik PLN Sambung (Bayar) & PDAM & 3 & 1037000 \\
\hline 17 |Juarsa & Buruh & Genteng & Papan & Keramik & Listrik PLN Sambung (Gratis) & Sumur Bor & 1 & 2850000 \\
\hline \begin{tabular}{l|l}
18 & Harmi \\
\end{tabular} & Tidak Bekerja & Genteng & Papan & Keramik & Listrik PLN & Sumur Bor & 2 & 1800000 \\
\hline \begin{tabular}{l|l}
19 & Sopyan \\
\end{tabular} & Buruh & Sirap (kayu) & Tembok & Semen & Listrik PLN & Sumur Bor & 2 & 2295000 \\
\hline 20. Muhammad Haris & Pegawai Negeri & Sirap (kaүu) & Papan & Keramik & Listrik PLN & PDAM & 3 & 5425000 \\
\hline 21 Budi Santoso & Pegawai Swasta & Sirap (kaүu) & Papan & Keramik & Listrik PLN & PDAM & 2 & 6820000 \\
\hline \begin{tabular}{l|l}
22 & Tanu Anggara Putra \\
\end{tabular} & Pegawai Swasta & Sirap (kayu) & Papan & Keramik & Listrik PLN & PDAM & 2 & 4170000 \\
\hline
\end{tabular}

Sumber: (Hasil Penelitian 2020)

Data penduduk miskin yang ada kemudian digunakan sebagai data yang diolah. Penyesuaian format data perlu dilakukan untuk mempermudah pengolahan data. Format data disesuaikan sehingga menjadi bentuk angka.

Tabel 2. Klasifikasi Penilaian

\begin{tabular}{|l|l|}
\hline 1 & Atap : \\
& 1 Asbes \\
& 2 Genteng (Tanah Liat) \\
& 3 Seng \\
& 4 Sirap (Kayu) \\
& 5 Genteng Metal \\
\hline 2 & Jenis Dinding : \\
& 1 Tembok \\
& 2 Tripleks \\
& 3 Bambu \\
& 4 Papan Kualitas Bagus \\
& 5 Papan Kualitas Jelek \\
\hline 3 & Jenis Lantai : \\
& 1 Papan Kualitas Bagus \\
& 2 Papan Kualitas Jelek \\
& 3 Semen \\
& 4 Tegel/Keramik \\
\hline
\end{tabular}

Sumber: (Hasil Penelitian 2020) 
Setelah klasifikasi penilaian ditentukan, data penduduk yang tidak mampu harus di transformasi ke dalam bentuk angka, berikut hasil transformasi teks ke dalam angka yang sudah ditentukan.

Tabel 3. Transformasi Nilai

\begin{tabular}{|c|c|c|c|c|c|c|c|c|}
\hline No Nama Kepala Ke keluapa & Pekenpiadn & Atap & Dinding & Lantial & Sunher Penerangan & Sunher Alit & Tanggungan & Pengegeluaran \\
\hline 1 Mad Enoh spon & 3 & & 1 & & 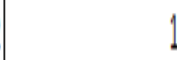 & 1 & & 3 \\
\hline 2|Wy. Atilh & 0 & & 1 & & 1 & 1 & & 3 \\
\hline 3 Nur Asith & 0 & 1 & 1 & & 1 & 1 & 1 & 3 \\
\hline A Badri Kuniawan & 2 & 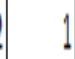 & 3 & & 1 & 1 & 3 & 3 \\
\hline 5 supardi & ! & 1 & 2 & & 2 & 1 & 5 & 2 \\
\hline 6||not & 0 & 1 & 2 & & 2 & 1 & 4 & 2 \\
\hline 7Nenih & 1 & 1 & 2 & & 2 & 2 & 0 & 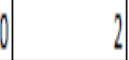 \\
\hline 8 (5) Shatsi & 2 & 2 & 2 & & 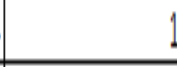 & 1 & 2 & 3 \\
\hline of Ahrod hal ham & 2 & 2 & 3 & & 1 & 2 & 2 & 2 \\
\hline 10 Manang: & $\underline{2}$ & 2 & 3 & & 1 & 2 & 3 & 3 \\
\hline 11 Anang & ! & 2 & 2 & & 2 & 1 & 2 & 3 \\
\hline 12 |aba & 0 & 2 & 5 & & 1 & 2 & 6 & 6 \\
\hline 13 Dona Nofilanyad & 3 & 2 & 5 & & 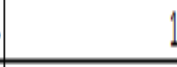 & 2 & 1 & 1 \\
\hline 14 Ahud Sulhardiman & j & ? & 5 & & 1 & 1 & 2 & 2) \\
\hline 15 Undan Rusmalta & 3 & 2 & 5 & & 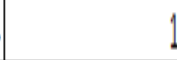 & 2 & 2 & 2 \\
\hline 16:E||lis Sullatiti & D & 2 & 5 & & 2 & 1 & 3 & 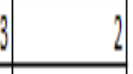 \\
\hline 17). Labist & 1 & 2 & 5 & & 3 & 2 & 1 & 1 \\
\hline 18 Harmi & 0 & ? & 5 & & 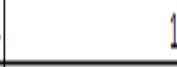 & 2 & ? & 2) \\
\hline 19 Sopyen & ! & 4 & 1 & 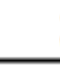 & 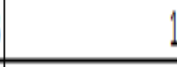 & 2 & 2 & 2 \\
\hline 20|Muhammad Haris & 4 & 4 & 5 & & 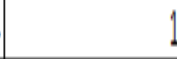 & 1 & 3 & 3 \\
\hline 211 Budi Santoso & 3 & 4 & 5 & & 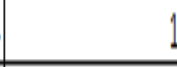 & 1 & 2 & 2 \\
\hline 2) Tand Angaga Puta & 3 & 4 & 5 & & 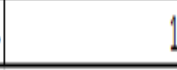 & 1 & $\underline{2}$ & 2 \\
\hline
\end{tabular}

Berdasarkan data yang telah digali sesuai dengan kriteria, dapat ditentukan centroid sebagai batas cluster. Digunakan 3 cluster yang dibentuk berdasarkan tiga kelompok prioritas penerima bantuan bedah rumah yang sebelumnya sudah ditetapkan oleh pihak Desa Ciomas. Karena ada 3 kelompok yang diharapkan maka dibutuhkan 3 pembatas kelompok (centroid), nilai centroid (M) dan cluster tersebut yang ditentukan secara acak. 


\begin{tabular}{cccc}
\multicolumn{4}{c}{ Tabel } \\
4. Nilai & Centroid (M) & Tahap Awal \\
\hline Centroid & JA & JD & JL \\
\hline M1 & 1 & 2 & 3 \\
\hline M2 & 2 & 5 & 4 \\
\hline M3 & 4 & 5 & 4 \\
\hline \multicolumn{4}{l}{ Sumber: (Hasil Penelitian 2020) }
\end{tabular}

\section{Proses Iterasi ke-1}

Pusat awal cluster atau centroid didapatkan secara random, untuk penentuan awal cluster diasumsikan :

Pusat Cluster $1:(1,2,3)$ Data Penduduk -7

Pusat Cluster 2 : $(2,5,4)$ Data Penduduk -18

Pusat Cluster 3 : $(4,5,4)$ Data Penduduk -22

Untuk mengukur jarak antara data dengan pusat cluster digunakan Rumus Euclidean

$\mathrm{d}(\mathbf{x}, \mathbf{y})=\sqrt{\sum_{i=1}^{n}\left(x_{i}-y_{i}\right)^{2}}$

Perhitungan data ke -1 (Iterasi ke - 1)

$$
\begin{aligned}
\mathrm{C} 1 & =\sqrt{(P 1 x-C 1 x)^{2}+(P 1 y-C 1 y)^{2}+(P 1 z-C 1 z)^{2}} \\
& =\sqrt{(1-1)^{2}+(1-2)^{2}+(2-3)^{2}} \\
& =\sqrt{0+1+1} \\
& =\sqrt{2}
\end{aligned}
$$

\section{Keterangan :}

P1x = Jenis Atap Penduduk ke-1

$\mathrm{C} 1 \mathrm{x}=$ Jenis Atap (Pusat Cluster 1)

P1y = Jenis Dinding Penduduk ke-1

C1y = Jenis Dinding (Pusat Cluster 1)

$\mathrm{P} 1 \mathrm{z}=$ Jenis Lantai Penduduk ke-1

$\mathrm{C} 1 \mathrm{z}=$ Jenis Lantai (Pusat Cluster 1$)$

Perhitungan dilakukan seterusnya sampai penduduk ke-22.

\section{Proses Iterasi ke-2}

Hitung Euclidean distance dari semua data ke titik pusat yang baru (C1, C2, C3) seperti yang telah dilakukan pada tahap 1. Setelah hasil perhitungan kita dapatkan, kemudian bandingkan hasil tersebut. Jika hasil posisi cluster pada iterasi ke 2 sama dengan posisi iterasi pertama, maka proses dihentikan, namun jika tidak maka proses dilanjutkan ke iterasi ke 3. 
Tabel 2. Nilai Centroid Baru

\begin{tabular}{cccc}
\hline Centroid & JA & JD & JL \\
\hline M1 & 1,25 & 1,8 & 2,5 \\
\hline M2 & 2 & 5 & 4 \\
\hline M3 & 4 & 5 & 4 \\
\hline \multicolumn{4}{c}{ Sumber: (Hasil Penelitian 2020) }
\end{tabular}

\section{KESIMPULAN DAN REKOMENDASI}

Pada iterasi ke 2 posisi cluster tidak berubah atau sama dengan posisi cluster pada iterasi pertama, maka proses iterasi dihentikan. Pada penelitian ini penduduk yang berhak mendapatkan bantuan bedah rumah adalah penduduk yang mempunyai nilai cluster paling besar atau kondisi fisik rumah terburuk yaitu Penduduk ke 20, 21 dan 22.

Sistem penilaian prioritas penduduk miskin yang menggunakan data mining metode Clustering K-Means dapat dipergunakan sebagai salah satu metode pengklasteran yang membantu keputusan dalam menentukan kelompok penduduk prioritas yang mendapatkan bedah rumah. Dan dengan adanya penelitian ini dapat menjadi acuan Kepala Desa untuk mengambil kebijakan tahap selanjutnya sesuai dengan knowledge yang dihasilkan oleh data mining metode clustering K-Means agar penilaian prioritas penduduk penerima bantuan bedah rumah bisa lebih berkualitas dan efektif.

\section{REFERENSI}

Arikunto, Suharsimi. (2000). Instrument Pada Penelitian Ilimiah.

Asroni, \& Adrian, R. (2015). Penerapan Metode K-Means untuk Clustering Mahasiswa Berdasarkan Nilai Akademik dengan Weka Interface Studi Kasus pada Jurusan Teknik Informatika UMM Magelang. Jurnal Ilmiah Semesta Teknika, 18(1), 76-82.

Astuti, F. (2013). Data Mining. Bandung: Dunia Komputer.

Badan Pusat Statistik. (2015). Data Rumah Tak Layak Huni

Eko Prasetyo. (2013). Data Mining : Konsep Dan Aplikasi Menggunakan Matlab. Journal of Chemical Information and Modeling.

Fina Nasari, \& Surya Darma, S. (2015). Penerapan K-Means Clustering Pada Data Penerimaan Mahasiswa Baru. Seminar Nasional Teknologi Informasi Dan Multimedia 2015, 73-78.

Han, J ,Kamber, P. (2011). Data Mining Concepts and Techniques (The Morgan).

Marfalino, H., \& Rahmi, A. (2015). Penerapan Analysis Clustering Pada Penjualan Komputer Dengan Perancanganan Aplikasi Data Mining Menggunakan Algoritma KMeans ( Study Kasus Toko Tri Buana Komputer Kota Solok ), 1(Senatkom), 50-59. 
Nurwati, N. (2008). Kemiskinan: Model Pengukuran, Permasalahan dan Alternatif Kebijakan. Jurnal Kependudukan Padjadjaran, 10(1), 1-11.

Pramita, A. L., Yasa, I. G. W. M., \& Marhaeni, A. A. I. N. (2015). Peranan Dana Bantuan Sosial Terhadap Kualitas Rumah Masyarakat Miskin Melalui Program Bedah Rumah Di Kabupaten Buleleng, E-Jurnal Ekonomi Dan Bisnis Universitas Udayana, 4(2), 106-124.

Purnamaningsih, C., Saptono, R., \& Aziz, A. (2016). Pemanfaatan Metode K-Means Clustering dalam Penentuan Penjurusan Siswa SMA. Jurnal Teknologi \& Informasi ITSmart, 3(1), 27.

Windarto, A. P. (2017). Penerapan Data Mining Pada Ekspor Buah-Buahan Menurut Negara Tujuan Menggunakan K-Means Clustering. Techno.COM, 16(4), 348-357. Retrieved from http://publikasi.dinus.ac.id/index.php/technoc/article/view/1447 Windha Mega Pradnya Dhuhita. (2016). Clustering Menggunakan Metode K-Means untuk Menentukan Status Gizi Balita. Jurnal Informatika, 15(2), 160-174.

Z, Z. A., \& Sarjono. (2016). Analisis Data Mining Untuk Menentukan Kelompok Prioritas Penerima Bantuan Bedah Rumah Menggunakan Metode Clustering K-Means ( Studi Kasus : Kantor Kecamatan Bahar Utara ). Jurnal Manajemen Sistem Informasi, 1(2), 159-170. 